\title{
Angiogenic and Inflammatory Properties of Psoriatic Arthritis
}

\author{
Toshiyuki Yamamoto \\ Department of Dermatology, Fukushima Medical University, Fukushima 960-1295, Japan \\ Correspondence should be addressed to Toshiyuki Yamamoto; toyamade@fmu.ac.jp
}

Received 22 April 2013; Accepted 15 May 2013

Academic Editors: G. Chodorowska, F. Guarneri, C.-C. Lan, M. Murakami, E. Pasmatzi, and W. Vanscheidt

Copyright (C) 2013 Toshiyuki Yamamoto. This is an open access article distributed under the Creative Commons Attribution License, which permits unrestricted use, distribution, and reproduction in any medium, provided the original work is properly cited.

\begin{abstract}
Psoriatic arthritis (PsA) is a chronic inflammatory arthropathy associated with psoriasis and included in seronegative spondyloarthropathy. PsA has several unique characteristics different from rheumatoid arthritis (RA), such as enthesopathy, dactylitis, and abnormal bone remodeling. As compared with synovitis of RA (pannus), proliferation of PsA synovium is mild and characterized by hypervascularity and increased infiltration of polymorphonuclear leukocytes in the synovial tissues. Angiogenesis plays a crucial role in cutaneous psoriasis, and several angiogenic factors such as vascular endothelial growth factor, interleukin-8, angiopoietin, tumor necrosis factor- $\alpha$ and transforming growth factor- $\beta$, are suggested to play an important role also in the pathophysiology of PsA. Further, IL-17 has various functions such as upregulation of proinflammatory cytokines, attraction of neutrophils, stimulation of keratinocytes, endothelial cell migration, and osteoclast formation via RANKL from activated synovial fibroblasts. Thus, IL-17 may be important in angiogenesis, fibrogenesis, and osteoclastogenesis in PsA. In this paper, roles of angiogenesis in the psoriatic synovium are discussed, which may strengthen the understanding of the pathogenesis of PsA.
\end{abstract}

\section{Introduction}

Psoriatic arthritis (PsA) is a chronic inflammatory arthropathy in association with psoriasis. PsA is classified as one of the seronegative spondyloarthropathy characterized by joint destruction with extra-articular involvement (i.e., eye, gut, and bowel). The involved joints present swelling, redness, and deformity to the end, which are usually periphery (main involvements are distal interphalangeal joints), but sacroiliac joints are less frequently affected. In nearly $70 \%$ of patients, cutaneous lesions precede the onset of joint pain, in $20 \%$ arthropathy starts before skin manifestations, and in $10 \%$ both are contemporary. Results of laboratory examination show elevated levels of erythrocyte sedimentation rate (ESR) and C-reactive protein (CRP) which reflect acute-phase inflammation. Rheumatoid factor (RF) and anti-cyclic citrullinated peptide (CCP) antibodies are usually negative. HLAB27 is found chiefly in patients with spondylitis type PsA. Radiographic features of joint space narrowing, erosions, osteolysis, new bone formation, enthesitis, spur formation, pencil-in-cup appearance, and bamboo spine. Although, in general, patients with severe cutaneous psoriasis often complain of arthralgia, skin severity and joint lesions are not always parallel. A number of studies have suggested genetic, environmental, and immunological aspects in the development of PsA. Although the pathophysiology of synovium of PsA is still not fully elucidated [1,2], previous studies suggested that the characteristic features of PsA synovium include hypervascularity and increased polymorphonuclear leukocyte infiltrates [3], which resembles that of spondyloarthritis, rather than rheumatoid arthritis (RA) [4]. Angiogenesis is suggested to play an important role in the early event in PsA. Herein, angiogenic properties in cutaneous and joint lesions of PsA are discussed.

\section{Angiogenesis of Cutaneous Psoriasis}

A number of studies have demonstrated that angiogenesis is crucial in the pathogenesis of psoriasis [5-7]. Early lesion of psoriasis is histologically characterized by capillary dilation and edema in the papillary dermis with perivascular lymphocytic infiltration, prior to the onset of epidermal proliferation. On the other hand, proangiogenic environment is induced by helper T-cells and regulatory T-cells. Development of psoriasis is in accordance with the elevated levels of vascular endothelial growth factor (VEGF) in the plasma and skin. Psoriatic keratinocytes produce several angiogenic cytokines, such as VEGF, interleukin-8 (IL-8), tumor necrosis 
factor- $\alpha$ (TNF- $\alpha$ ), and transforming growth factor- $\beta$ (TGF$\beta$ ). Additionally, infiltrating neutrophils can be a source of VEGF, which induces neutrophil chemotaxis in an autocrine amplification manner [8]. VEGF receptors (VEGFR-1 and R2) are overexpressed in psoriatic skin. Further, VEGF can enhance VEGFR expression in keratinocytes. Transcriptional activation of VEGF and its receptor, VEGFR-1, are mediated by hypoxia-inducible factors (HIFs). Expression of HIF isoforms is strongly upregulated in psoriatic skin, and HIF-1 colocalizes with VEGF in the psoriatic epidermis [9].

In mice, VEGF overexpressed selectively in basal keratinocytes exhibited a chronic skin inflammation with increased numbers of tortuous capillaries and expression of VEGFR-1 and VEGFR-2 [10]. Other studies showed that VEGF transgenic mice whose appearances and immunopathology looked similar to human psoriatic skin [11]. Additionally, overexpression of angiopoietin receptor, Tie2, develops psoriasis-like phenotypes in mice [12]. IL-9 has an angiogenic effect both in vitro and in vivo [13], and intradermal injection of IL-9 induces VEGF and CD31 overexpression [13]. Other studies also demonstrated that mice models for psoriasis are ameliorated by interfering angiogenesis by recombinant disintegrin domain of ADAM-15 [14] and pigment epithelium-derived factor [15], suggesting that angiogenesis is a possible therapeutic target of psoriasis.

\section{Angiogenesis of Joint Lesions in PsA}

3.1. Cellular Infiltrates. Previous studies showed that synovial T-cells in PsA are functionally active, which may migrate also into the psoriatic skin as well as inflamed enthesis. Tcells, cytokines, chemokines, and matrix metalloproteinases (MMPs) are supposed to play important roles in the inflammatory process leading to the destruction of joint tissues. Not only T-cells but also B-cells are seen in the synovium, occasionally forming primitive germinal centers; however the implication of B-cell infiltration is unclear. Abundant T-cells, both $\mathrm{CD} 4+$ and $\mathrm{CD} 8+$ with clonal or oligoclonal expansions, are infiltrated in the synovial tissues of PsA [16], most of which are activated memory T-cells expressing HLA-DR and CD45RO [17]. T-cells bearing the same T-cell receptor $\mathrm{V} \beta$ subsets are present in both joint and skin lesions [18]. Recruitment of T-cells into the synovium may be mediated by chemokines, such as CCL2, CXCL13, CCL21, and CCL22 $[19,20]$. CCL22 (macrophage-derived chemokine) was demonstrated to be expressed in the synovial membrane and produced in the synovial fluids of PsA [21]. CCL22 and its ligand CCR4 play an important role in attracting skin-specific memory T-cells to the synovial tissues [2]. T-cell-derived cytokines such as IL-1 $\beta$, IL-2, IL-10, interferon- $\gamma$ (IFN- $\gamma$ ), and TNF- $\alpha$ are dominantly detected in the synovium $[22,23]$. On the other hand, recent advances indicate that psoriasis is a Th17-mediated inflammatory disease [24]. Th17 cells produce IL-17, which promotes neutrophil migration and proliferates downstream inflammatory molecules. Also, Th17 cells secret IL-6, IL-21, IL-22, TNF- $\alpha$, and IFN- $\gamma$. IL-23 is their downstream cytokine, promotes the differentiation and growth of IL-17, and upregulates IL-22. IL-20 and IL-22 activate STAT3 in keratinocytes [25]. Thus, the IL-23/IL-17 inflammatory pathway is central to the pathogenesis of psoriasis. IL-23 is overproduced by dendritic cells and keratinocytes. IL-23 activates downstream mediators such as STAT3 and IL-22. Subcutaneous injections of IL-23 in mice induced psoriasis-like changes of erythema and induration as well as histological features such as acanthosis and parakeratosis [26, 27], and this IL-23-induced psoriasis-like inflammation requires CCR-6 [28]. IL-23 transgenic mice show inflammatory cutaneous reaction resembling psoriasis with increased number of T-cells and Langerhans cells [29].

Infiltration of CD68+ macrophages was less in synovium of PsA as compared with RA, but expression of macrophagederived cytokines such as TNF- $\alpha$, IL-1, IL-10, and IL-15 was detected in the lining layer and around the vessels [30]. On the contrary, the number of CD163+ macrophages was greater in PsA than in RA [31]. To determine the balance of M1/M2 type macrophages in the PsA synovium, further studies are necessary. Synovial macrophages participate in stimulating angiogenesis.

Neutrophils play an important role in the lesional skin of psoriasis, and also neutrophil infiltration is seen in the synovium. As compared with rheumatoid synovial membranes, infiltration of polymorphonuclear cells is prominent [31].

Dendritic cells (DCs) populations are Langerhans cells, myeloid DCs, and plasmacytoid DCs. Myeloid CD11c+DCs are subdivided into resident and myeloid inflammatory DCs, depending on their expression of $\mathrm{CD1c}$, and in the psoriatic skin, CD11c+CD1c- population is increased in number [32]. Both myeloid DCs and plasmacytoid DCs were present in the synovial fluids of PsA [33, 34]. A large population of these inflammatory DCs express TNF- $\alpha$ and inducible nitric oxide synthase (iNOS) and are considered to be equivalent to Tip-DCs. Further, these inflammatory DCs produce IL-20 and IL-23 $[35,36]$. Thus, these inflammatory DCs are suggested to play a central role in psoriasis. On the other hand, antimicrobial peptide cathelicidin (LL37) induces IFN- $\alpha$ production by plasmacytoid DCs, when complexed with selfDNA. IFN- $\alpha$ has been implicated in the induction of psoriasis [37], and inhibition of IFN- $\alpha$ prevented the development of psoriatic lesions in mice grafted with human psoriatic skin [38]. IFN- $\alpha$ enhances the activation of CD8+ T-cells by antigen-presenting cells [39]. In addition, IFN- $\alpha$ amplifies cutaneous inflammation via the induction of chemokines, such as CXCL9, CXCL10, and CXCL11, which recruit their receptor CXCR3 expressing lymphocytes [40], including CD8+ T-cells. Also, plasmacytoid DCs isolated from synovial fluids express CXCR3 and CXCR4 [36], the receptors for CXCL10 and CXCL11, and for CXCL12, respectively. Thus, chemokine-driven recruitment of plasmacytoid DCs into the synovium could be important in the pathogenesis of PsA. Further, cathelicidin stimulates angiogenesis [41].

Mast cells are increased in number in the synovium in PsA as well as enhanced expression of stem cell factor, a mast cell growth factor [42]. Mast cells greatly contribute to angiogenesis, and mast cell degranulation in human induces expression of E-selectin on vascular endothelial cells [43], mast cell-derived TNF- $\alpha$ has the potential to induce the early expression of E-selectin [44]. E-selectin was preferentially expressed in the blood vessels in the synovium [42], which 


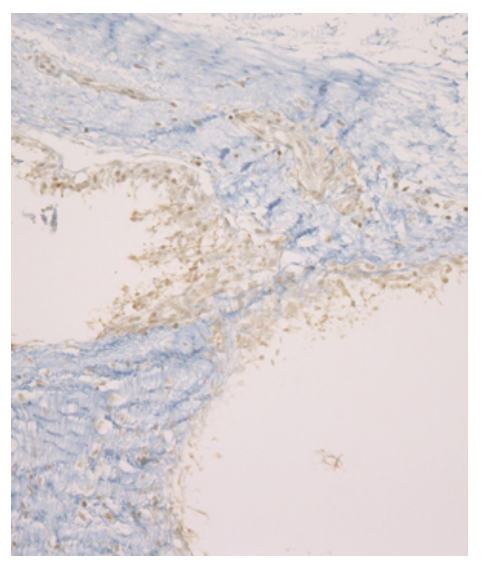

(a)

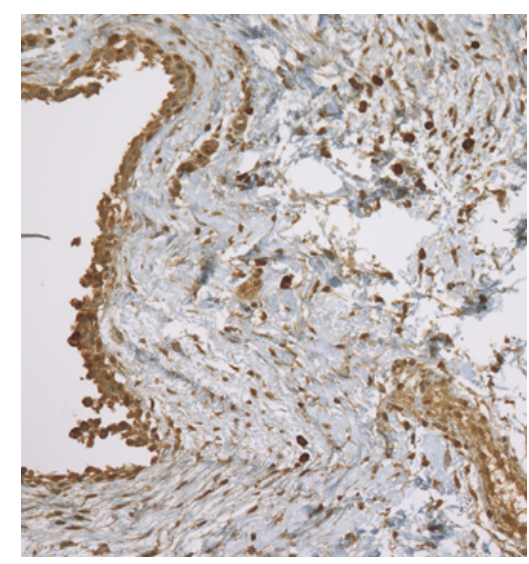

(b)

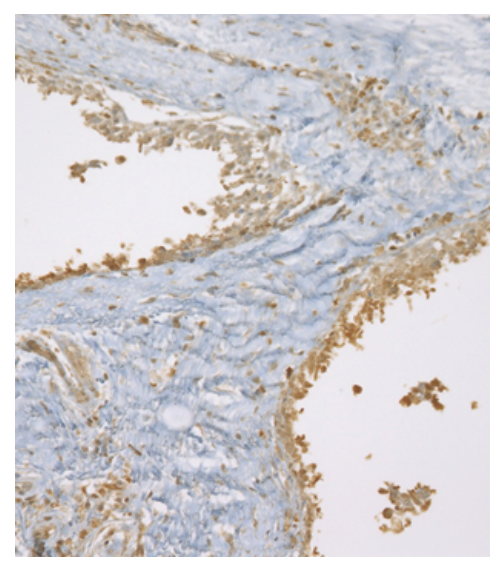

(c)

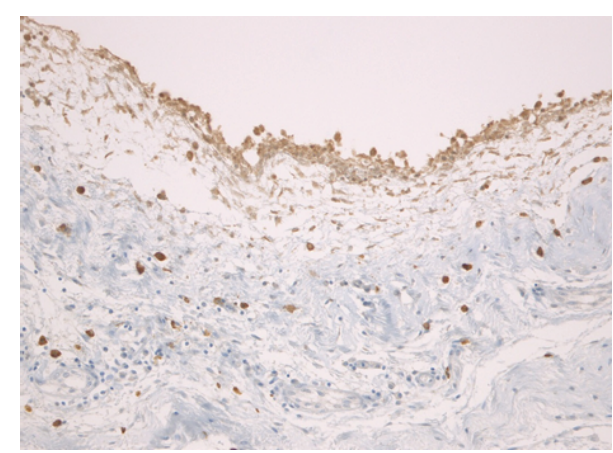

(d)

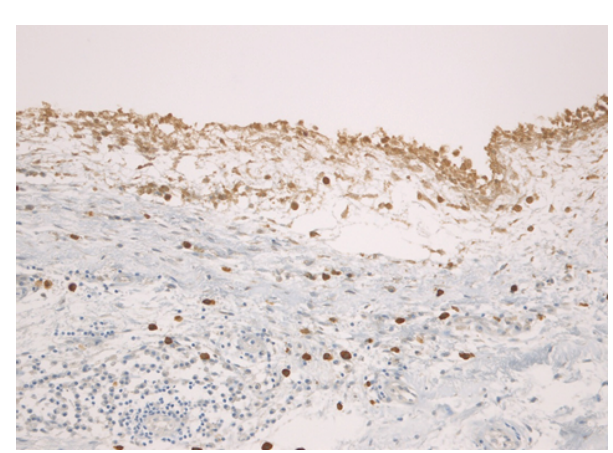

(e)

FIGURE 1: Immunohistological localization of angiogenesis markers (a) VEGF, (b) flt-1, (c) flk-1, (d) angiopoietin, (e) HIF-1 $\alpha$ ) in the PsA synovium. Paraffin-embedded sections were stained by avidin-biotin peroxidase technique.

suggests that the synovium of PsA is in a continuous state of endothelial activation. Mast cell-derived mediators may also contribute to the synovial hyperplasia and angiogenesis.

3.2. Vascular Changes. Synovial angiogenesis is central to synovial proliferation. Angiogenic mediators secreted by synovial tissue cells and/or synovial tissue infiltrating cells are involved in neovascularization. Morphological vascular changes such as tortuous and elongated features are shown by microscopic examination in the blood vessels of synovial membrane of PsA [45]. Angiogenesis is also evident in the psoriatic synovium at early stages and expression of angiogenic cytokines such as VEGF, TGF- $\beta$, and angiopoietins [46]. VEGF may be upregulated within the synovium following stimulation with TNF- $\alpha$ and IL-1 secreted by synovial cells and also infiltrating cells. Expression of VEGF as well as VEGF receptors (VEGFR-1/Flt1 and VEGFR-2/KDR) is detected in the PsA synovium (Figures $1(\mathrm{a})-1(\mathrm{c})$ ). TNF- $\alpha$ is detected in the synovial membrane of PsA, which upregulates angiogenic cytokines [47]. TNF- $\alpha$ upregulates the production of proangiogenic VEGF-A splice variants. AntiTNF therapies reduced VEGF levels in the sera and skin of PsA patients $[48,49]$, suggesting that TNF- $\alpha$ greatly contributes to angiogenesis associated with PsA. Also, TNF- $\alpha$ enhances endothelial cells to express adhesion molecules such as intercellular adhesion molecule-1 (ICAM-1), vascular cell adhesion molecule-1 (VCAM-1), and E-selectin [50]. Blood vessels in PsA synovium express a variety of adhesion molecules such as ICAM-1, VCAM-1, and E-selectin [51], which promote leukocyte migration to inflammatory sites. Angiopoietin- 1 and -2 and their receptor Tie- 2 are involved in angiogenic processes. Angiopoietin-2 is an effector downstream molecule of VEGF signaling pathway and promotes adhesion by sensitizing endothelial cells to TNF- $\alpha$ and modulating TNF- $\alpha$ induced expression of adhesion molecules on endothelial cells [52]. Recent studies have demonstrated that VEGF and Angiopoietin-2 induced Notch expression, which mediates synovial angiogenesis [53]. In addition to a number of properties described before, IL-17 stimulates endothelial cell migration and cord formation [54] and plays an important role in arthritis. Actl (nuclear factor-kappa B (NF- $\kappa \mathrm{B}$ ) activator 1) is an adaptor protein for the IL-17 receptor and modulates downstream mediators of proinflammatory genes [55]. Mast cells are one of the major sources of IL-17 in the synovium [56]. Hypoxia is induced in joint inflammation. Expression of angiopoietin and HIF- $1 \alpha$ is detected in the PsA synovium (Figures $1(\mathrm{~d})$ and $1(\mathrm{e})$ ).

3.3. Synovial Fibroblasts. In the inflamed synovium, synovial fibroblasts are stimulated by proinflammatory cytokines and may change the phenotype which secret inflammatory mediators, matrix-degrading enzymes, and chemotactic 
molecules. Toll-like receptors (TLRs) play an important role in the regulation of innate and adaptive immune responses. Recent findings demonstrate functionally active TLRs on synovial fibroblasts are involved in the regulation of inflammatory responses in the synovial tissues of RA and spondylarthropathy [57]. Stimulation of TLR-2 pathway in synovial fibroblasts with TNF- $\alpha$ induces translocation of NF- $\kappa$ B, which leads to the secretion of proinflammatory cytokines and MMPs [58]. MMP is speculated to play an important role in joint inflammation and tissue destruction. TLRs activate signaling pathways inducing a number of mediators including MMPs $[59,60]$. So far, very few data are available on MMPs expression in the synovial tissues of PsA [61]. MMP-1 and MMP- 3 are found in the sublining layer cell populations as well as in some lining layer cells, which may be responsible for the severity of the joint symptoms of PsA. Overexpression of dominant-negative forms of MyD 88 significantly downregulated TNF- $\alpha$ and also MMPs in cultured synovial membranes isolated from RA patients [62]. Further, TLR-4deficient mice showed reduced joint inflammation [63]. TLR2 and TLR-4 may play an important role in the production of MMPs, which contribute to the joint destruction in the synovium. Enhanced expression of TLR-2 and TLR-4 in the PsA synovium has been reported [64]. Increased expression of TLR-2 and -4 have been seen on CD4+ CD28+ T-cells in the peripheral blood of patients with PsA [65]. Expression of TLR- 2 and TLR- 4 is upregulated by TNF- $\alpha$ and IFN- $\gamma$, as well as IL-1 and lipopolysaccharide (LPS) [66].

3.4. Synovial Fluids. CD8+ T-cells are significantly increased with clonal expansions in synovial fluids, but CD4+ T-cells are few $[16,67]$. VLA-1 integrin expressing T-cells isolated from synovial fluids display an oligoclonal repertoire [68]. High levels of TNF- $\alpha$, TNF- $\alpha$ receptors, IL-1, IL-6, IL8, IL-13, and other proinflammatory cytokines are found in the synovial fluids, which however are not as much as those contained in RA synovium [69-71]. IL-22 is a downstream effector of IL-23-induced inflammation and epidermal acanthosis in murine models [26]. IL-22 regulates the differentiation and migration of keratinocytes as well as production of antimicrobial proteins from keratinocytes $[25,72]$. Thus, IL-22 plays a crucial role in psoriasis. IL-22 levels are significantly elevated in synovial fluids [73]. IL-22 induced significant proliferation of synoviocytes, suggesting that IL-22 contributes to the synovial proliferation in PsA. Interestingly, IL-22 enhances the expression of MMP-1 and MMP-3 [74], suggesting an important role of Th17/Th22 cytokines in the local PsA synovial tissues. CXC chemokines attract neutrophil granulocytes and T-cells. CXCL9 production was significantly high in the synovial fluids of PsA [75], suggesting that CXCL9 is an important chemokine in autoimmune arthritis of PsA. Significant roles of MMP-2 and MMP-9 in angiogenesis have been explored. MMP-9 levels are significantly higher in the synovial fluids of early PsA [76].

\section{Conclusion}

Angiogenic pathways are implicated to play an important role in the pathogenesis of PsA, which drives inflammation, synovial fibroblasts activation, and joint damages. Inhibition of angiogenesis targeting or controlling of angiogenic molecules or angiogenesis-induced cellular events may lead to the novel therapies for PsA.

\section{Conflict of Interests}

The author states no conflict of interests.

\section{References}

[1] D. L. Boyle and A. Kavanaugh, "The pathobiology of psoriatic synovium," Current Opinion in Rheumatology, vol. 20, no. 4, pp. 404-407, 2008.

[2] A. W. R. Van Kuijk and P. P. Tak, "Synovitis in psoriatic arthritis: immunohistochemistry, comparisons with rheumatoid arthritis, and effects of therapy," Current Rheumatology Reports, vol. 13, no. 4, pp. 353-359, 2011.

[3] T. Yamamoto, "Psoriatic arthritis: from a dermatological perspective," European Journal of Dermatology, vol. 21, no. 5, pp. 660-666, 2011.

[4] E. Kruithof, D. Baeten, L. De Rycke et al., "Synovial histopathology of psoriatic arthritis, both oligo- and polyarticular, resembles spondyloarthropathy more than it does rheumatoid arthritis," Arthritis Research \& Therapy, vol. 7, no. 3, pp. R569-R580, 2005.

[5] R. A. Chua and J. L. Arbiser, "The role of angiogenesis in the pathogenesis of psoriasis," Autoimmunity, vol. 42, no. 7, pp. 574$579,2009$.

[6] R. Heidenreich, M. Röcken, and K. Ghoreschi, "Angiogenesis drives psoriasis pathogenesis," International Journal of Experimental Pathology, vol. 90, no. 3, pp. 232-248, 2009.

[7] M. Canavese, F. Altruda, T. Ruzicka, and J. Schauber, "Vascular endothelial growth factor (VEGF) in the pathogenesis of psoriasis-a possible target for novel therapies?" Journal of Dermatological Science, vol. 58, no. 3, pp. 171-176, 2010.

[8] M. Ancelin, S. Chollet-Martin, M. A. Hervé, C. Legrand, J. El Benna, and M. Perrot-Applanat, "Vascular endothelial growth factor VEGF189 induces human neutrophil chemotaxis in extravascular tissue via an autocrine amplification mechanism," Laboratory Investigation, vol. 84, no. 4, pp. 502-512, 2004.

[9] C. Rosenberger, C. Solovan, A. D. Rosenberger et al., "Upregulation of hypoxia-inducible factors in normal and psoriatic skin," Journal of Investigative Dermatology, vol. 127, no. 10, pp. 24452452, 2007.

[10] M. Detmar, L. F. Brown, M. P. Schön et al., "Increased microvascular density and enhanced leukocyte rolling and adhesion in the skin of VEGF transgenic mice," Journal of Investigative Dermatology, vol. 111, no. 1, pp. 1-6, 1998.

[11] Y. Xia, B. Li, D. Hylton, M. Detmar, G. D. Yancopoulos, and J. S. Rudge, "Transgenic delivery of VEGF to mouse skin leads to an inflammatory condition resembling human psoriasis," Blood, vol. 102, no. 1, pp. 161-168, 2003.

[12] D. Voskas, N. Jones, P. Van Slyke et al., "A cyclosporine-sensitive psoriasis-like disease produced in Tie2 transgenic mice," American Journal of Pathology, vol. 166, no. 3, pp. 843-855, 2005.

[13] T. P. Singh, M. P. Schön, K. Wallbrecht, A. Gruber-Wackernagel, X.-J. Wang, and P. Wolf, "Involvement of IL-9 in Th17-associated inflammation and angiogenesis of psoriasis," PLOS ONE, vol. 8, no. 1, Article ID e51752, 2013. 
[14] J. R. Zibert, K. Wallbrecht, M. Schön et al., "Halting angiogenesis by non-viral somatic gene therapy alleviates psoriasis and murine psoriasiform skin lesions," Journal of Clinical Investigation, vol. 121, no. 1, pp. 410-421, 2011.

[15] R. Abe, S. Yamagishi, Y. Fujita et al., "Topical application of anti-angiogenic peptides based on pigment epithelium-derived factor can improve psoriasis," Journal of Dermatological Science, vol. 57, no. 3, pp. 183-191, 2010.

[16] P. J. Costello, R. J. Winchester, S. A. Curran et al., "Psoriatic arthritis joint fluids are characterized by CD8 and CD4 T cell clonal expansions that appear antigen driven," Journal of Immunology, vol. 166, no. 4, pp. 2878-2886, 2001.

[17] T. Yamamoto, H. Yokozeki, and K. Nishioka, "Clinical analysis of 21 patients with psoriasis arthropathy," Journal of Dermatology, vol. 32, no. 2, pp. 84-90, 2005.

[18] L. Borgato, A. Puccetti, R. Beri et al., "The T cell receptor repertoire in psoriatic synovitis is restricted and $\mathrm{T}$ lymphocytes expressing the same TCR are present in joint and skin lesions," Journal of Rheumatology, vol. 29, no. 9, pp. 1914-1919, 2002.

[19] E. L. Ross, D. D'Cruz, and W. J. W. Morrow, "Localized monocyte chemotactic protein-1 production correlates with $\mathrm{T}$ cell infiltration of synovium in patients with psoriatic arthritis," Journal of Rheumatology, vol. 27, no. 10, pp. 2432-2443, 2000.

[20] J. D. Cañete, B. Santiago, T. Cantaert et al., "Ectopic lymphoid neogenesis in psoriatic arthritis," Annals of the Rheumatic Diseases, vol. 66, no. 6, pp. 720-726, 2007.

[21] H. A. Flytlie, M. Hvid, E. Lindgreen et al., "Expression of MDC/ CCL22 and its receptor CCR4 in rheumatoid arthritis, psoriatic arthritis and osteoarthritis," Cytokine, vol. 49, no. 1, pp. 24-29, 2010.

[22] G. Partsch, E. Wagner, B. F. Leeb, H. Bröll, A. Dunky, and J. S. Smolen, "T cell derived cytokines in psoriatic arthritis synovial fluids," Annals of the Rheumatic Diseases, vol. 57, no. 11, pp. 691693, 1998.

[23] A. W. R. Van Kuijk, P. Reinders-Blankert, T. J. M. Smeets, B. A. C. Dijkmans, and P. P. Tak, "Detailed analysis of the cell infiltrate and the expression of mediators of synovial inflammation and joint destruction in the synovium of patients with psoriatic arthritis: implications for treatment," Annals of the Rheumatic Diseases, vol. 65, no. 12, pp. 1551-1557, 2006.

[24] A. Di Cesare, P. Di Meglio, and F. O. Nestle, "The IL-23Th17 axis in the immunopathogenesis of psoriasis," Journal of Investigative Dermatology, vol. 129, no. 6, pp. 1339-1350, 2009.

[25] K. Wolk, H. S. Haugen, W. Xu et al., "IL-22 and IL-20 are key mediators of the epidermal alterations in psoriasis while IL-17 and IFN- $\gamma$ are not," Journal of Molecular Medicine, vol. 87, no. 5, pp. 523-536, 2009.

[26] Y. Zheng, D. M. Danilenko, P. Valdez et al., "Interleukin-22, a TH17 cytokine, mediates IL-23-induced dermal inflammation and acanthosis," Nature, vol. 445, no. 7128, pp. 648-651, 2007.

[27] J. R. Chan, W. Blumenschein, E. Murphy et al., "IL-23 stimulates epidermal hyperplasia via TNF and IL-20R2-dependent mechanisms with implications for psoriasis pathogenesis," Journal of Experimental Medicine, vol. 203, no. 12, pp. 2577-2587, 2006.

[28] M. N. Hedrick, A. S. Lonsdorf, A. Shirakawa et al., "CCR6 is required for IL-23-induced psoriasis-like inflammation in mice," Journal of Clinical Investigation, vol. 119, no. 8, pp. 23172329, 2009.

[29] T. Kopp, P. Lenz, C. Bello-Fernandez, R. A. Kastelein, T. S. Kupper, and G. Stingl, "IL-23 production by cosecretion of endogenous p19 and transgenic p40 in keratin 14/p40 transgenic mice: evidence for enhanced cutaneous immunity," Journal of Immunology, vol. 170, no. 11, pp. 5438-5444, 2003.

[30] C. L. Danning, G. G. Illei, C. Hitchon, M. R. Greer, D. T. Boumpas, and I. B. McInnes, "Macrophage-derived cytokine and nuclear factor kappaB p65 expression in synovial membrane and skin of patients with psoriatic arthritis," Arthritis \& Rheumatism, vol. 43, no. 6, pp. 1244-1256, 2000.

[31] D. Baeten, E. Kruithof, L. De Rycke et al., "Infiltration of the synovial membrane with macrophage subsets and polymorphonuclear cells reflects global disease activity in spondyloarthropathy," Arthritis Research \& Therapy, vol. 7, no. 2, pp. R359-R369, 2005.

[32] L. C. Zaba, I. Cardinale, P. Gilleaudeau et al., "Amelioration of epidermal hyperplasia by TNF inhibition is associated with reduced Th17 responses," Journal of Experimental Medicine, vol. 204, no. 13, pp. 3183-3194, 2008.

[33] S. L. Jongbloed, M. C. Lebre, A. R. Fraser et al., "Enumeration and phenotypical analysis of distinct dendritic cell subsets in psoriatic arthritis and rheumatoid arthritis," Arthritis Research \& Therapy, vol. 8, no. 1, article R15, 2005.

[34] F. Wang, E. Lee, M. A. Lowes et al., "Prominent production of IL-20 by $\mathrm{CD}^{+} 8^{+} / \mathrm{CD}_{11 c^{+}}$Myeloid-derived cells in psoriasis: gene regulation and cellular effects," Journal of Investigative Dermatology, vol. 126, no. 7, pp. 1590-1599, 2006.

[35] E. Guttman-Yassky, M. A. Lowes, J. Fuentes-Duculan et al., "Low expression of the IL-23/Th17 pathway in atopic dermatitis compared to psoriasis," Journal of Immunology, vol. 181, no. 10, pp. 7420-7427, 2008.

[36] R. Lande, E. Giacomini, B. Serafini et al., "Characterization and recruitment of plasmacytoid dendritic cells in synovial fluid and tissue of patients with chronic inflammatory arthritis," Journal of Immunology, vol. 173, no. 4, pp. 2815-2824, 2004.

[37] F. O. Nestle and M. Gilliet, "Defining upstream elements of psoriasis pathogenesis: an emerging role for interferon $\alpha$," Journal of Investigative Dermatology, vol. 125, no. 5, pp. 14-15, 2005.

[38] F. O. Nestle, C. Conrad, A. Tun-Kyi et al., "Plasmacytoid predendritic cells initiate psoriasis through interferon- $\alpha$ production," Journal of Experimental Medicine, vol. 202, no. 1, pp. 135-143, 2005.

[39] J. M. Curtsinger, J. O. Valenzuela, P. Agarwal, D. Lins, and M. F. Mescher, "Cutting edge: type I IFNs provide a third signal to CD8 T cells to stimulate clonal expansion and differentiation," Journal of Immunology, vol. 174, no. 8, pp. 4465-4469, 2005.

[40] R. Koczulla, G. Von Degenfeld, C. Kupatt et al., "An angiogenic role for the human peptide antibiotic LL-37/hCAP-18," Journal of Clinical Investigation, vol. 111, no. 11, pp. 1665-1672, 2003.

[41] J. Wenzel, E. Wörenkämper, S. Freutel et al., "Enhanced type I interferon signalling promotes Thl-biased inflammation in cutaneous lupus erythematosus," Journal of Pathology, vol. 205, no. 4, pp. 435-442, 2005.

[42] T. Yamamoto, M. Matsuuchi, K. Watanabe, I. Katayama, and K. Nishioka, "Mast cells in the synovium of patients with psoriasis arthropathy," Dermatology, vol. 195, no. 1, pp. 73-74, 1997.

[43] L. M. Klein, R. M. Lavker, W. L. Matis, and G. F. Murphy, "Degranulation of human mast cells induces an endothelial antigen central to leukocyte adhesion," Proceedings of the National Academy of Sciences of the United States of America, vol. 86, no. 22, pp. 8972-8976, 1989.

[44] L. J. Walsh, G. Trinchieri, H. A. Waldorf, D. Whitaker, and G. F. Murphy, "Human dermal mast cells contain and release tumor necrosis factor $\alpha$, which induces endothelial leukocyte adhesion 
molecule 1," Proceedings of the National Academy of Sciences of the United States of America, vol. 88, no. 10, pp. 4220-4224, 1991.

[45] R. J. Reece, J. D. Canete, W. J. Parsons, P. Emery, and D. J. Veale, "Distinct vascular patterns of early synovitis in psoriatic, reactive, and rheumatoid arthritis," Arthritis \& Rheumatism, vol. 42, no. 7, pp. 1481-1484, 1999.

[46] U. Fearon, K. Griosios, A. Fraser et al., "Angiopoietins, growth factors, and vascular morphology in early arthritis," Journal of Rheumatology, vol. 30, no. 2, pp. 260-268, 2003.

[47] D. J. Veale, C. Ritchlin, and O. FitzGerald, "Immunopathology of psoriasis and psoriatic arthritis," Annals of the Rheumatic Diseases, vol. 64, no. 2, supplement, pp. ii26-ii29, 2005.

[48] A. Mastroianni, E. Minutilli, A. Mussi et al., "Cytokine profiles during infliximab monotherapy in psoriatic arthritis," British Journal of Dermatology, vol. 153, no. 3, pp. 531-536, 2005.

[49] P. Cordiali-Fei, E. Trento, G. D’Agosto et al., "Effective therapy with anti-TNF- $\alpha$ in patients with psoriatic arthritis is associated with decreased levels of metalloproteinases and angiogenic cytokines in the sera and skin lesions," Annals of the New York Academy of Sciences, vol. 1110, pp. 578-589, 2007.

[50] S. J. Leibovich, P. J. Polverini, H. M. Shepard, D. M. Wiseman, V. Shively, and N. Nuseir, "Macrophage-induced angiogenesis is mediated by tumour necrosis factor- $\alpha$," Nature, vol. 329 , no. 6140, pp. 630-632, 1987.

[51] D. Veale, G. Yanni, S. Rogers, L. Barnes, B. Bresnihan, and O. FitzGerald, "Reduced synovial membrane macrophage numbers, ELAM-1 expression, and lining layer hyperplasia in psoriatic arthritis as compared with rheumatoid arthritis," Arthritis \& Rheumatism, vol. 36, no. 7, pp. 893-900, 1993.

[52] U. Fiedler, Y. Reiss, M. Scharpfenecker et al., "Angiopoietin-2 sensitizes endothelial cells to TNF- $\alpha$ and has a crucial role in the induction of inflammation," Nature Medicine, vol. 12, no. 2, pp. 235-239, 2006.

[53] W. Gao, C. Sweeney, C. Walsh et al., "Notch signaling pathways mediate synovial angiogenesis in response to vascular endothelial growth factor and angiopoietin 2," Annals of Rheumatic Disease, vol. 72, no. 6, pp. 1080-1088, 2013.

[54] M. Numasaki, J. Fukushi, M. Ono et al., "Interleukin-17 promotes angiogenesis and tumor growth," Blood, vol. 101, no. 7, pp. 2620-2627, 2003.

[55] M. S. Doyle, E. S. Collins, O. M. FitzGerald, and S. R. Pennington, "New insight into the functions of the interleukin-17 receptor adaptor protein Actl in psoriatic arthritis," Arthritis Research \& Therapy, vol. 14, no. 5, article 226, 2012.

[56] T. Noordenbos, N. Yeremenko, I. Gofita et al., "Interleukin17-positive mast cells contribute to synovial inflammation in spondylarthritis," Arthritis \& Rheumatism, vol. 64, no. 1, pp. 99109, 2012.

[57] L. De Rycke, B. Vandooren, E. Kruithof, F. De Keyser, E. M. Veys, and D. Baeten, "Tumor necrosis factor $\alpha$ blockade treatment down-modulates the increased systemic and local expression of Toll-like receptor 2 and Toll-like receptor 4 in spondylarthropathy," Arthritis \& Rheumatism, vol. 52, no. 7, pp. 21462158, 2005.

[58] R. Seibl, T. Birchler, S. Loeliger et al., "Expression and regulation of Toll-like receptor 2 in rheumatoid arthritis synovium," American Journal of Pathology, vol. 162, no. 4, pp. 1221-1227, 2003.

[59] Q. Zhang, W. Hui, G. J. Litherland et al., "Differential Toll-like receptor-dependent collagenase expression in chondrocytes," Annals of the Rheumatic Diseases, vol. 67, no. 11, pp. 1633-1641, 2008.
[60] F. Brentano, D. Kyburz, and S. Gay, "Toll-like receptors and rheumatoid arthritis," Methods in Molecular Biology, vol. 517, pp. 329-343, 2009.

[61] D. Kane, L. E. Jensen, S. Grehan, A. S. Whitehead, B. Bresnihan, and O. Fitzgerald, "Quantitation of metalloproteinase gene expression in rheumatoid and psoriatic arthritis synovial tissue distal and proximal to the cartilage-pannus junction," Journal of Rheumatology, vol. 31, no. 7, pp. 1274-1280, 2004.

[62] S. M. Sacre, E. Andreakos, S. Kiriakidis et al., "The toll-like receptor adaptor proteins MyD88 and Mal/TIRAP contribute to the inflammatory and destructive processes in a human model of rheumatoid arthritis," American Journal of Pathology, vol. 170, no. 2, pp. 518-525, 2007.

[63] S. Abdollahi-Roodsaz, L. A. B. Joosten, M. I. Koenders et al., "Stimulation of TLR2 and TLR4 differentially skews the balance of $\mathrm{T}$ cells in a mouse model of arthritis," Journal of Clinical Investigation, vol. 118, no. 1, pp. 205-216, 2008.

[64] L. Candia, J. Marquez, C. Hernandez, A. H. Zea, and L. R. Espinoza, "Toll-like receptor-2 expression is upregulated in antigen-presenting cells from patients with psoriatic arthritis: a pathogenic role for innate immunity?" Journal of Rheumatology, vol. 34, no. 2, pp. 374-379, 2007.

[65] B. Raffeiner, C. Dejaco, C. Duftner et al., "Between adaptive and innate immunity: TLR4-mediated perforin production by CD28null T-helper cells in ankylosing spondylitis," Arthritis Research \& Therapy, vol. 7, no. 6, pp. R1412-R1420, 2005.

[66] B. Beutler, "Inferences, questions and possibilities in Toll-like receptor signalling," Nature, vol. 430, no. 6996, pp. 257-263, 2004.

[67] P. Costello, B. Bresnihan, C. O’Farrelly, and O. Fitzgerald, "Predominance of $\mathrm{CD}^{+} \mathrm{T}$ lymphocytes in psoriatic arthritis," Journal of Rheumatology, vol. 26, no. 5, pp. 1117-1124, 1999.

[68] I. Goldstein, A. J. Simon, S. B. Horin et al., "Synovial VLA-1+ $\mathrm{T}$ cells display an oligoclonal and partly distinct repertoire in rheumatoid and psoriatic arthritis," Clinical Immunology, vol. 128, no. 1, pp. 75-84, 2008.

[69] G. Partsch, G. Steiner, B. F. Leeb, A. Dunky, H. Bröll, and J. S. Smolen, "Highly increased levels of tumor necrosis factor- $\alpha$ and other proinflammatory cytokines in psoriatric arthritis synovial fluid," Journal of Rheumatology, vol. 24, no. 3, pp. 518-523, 1997.

[70] G. Partsch, E. Wagner, B. F. Leeb, A. Dunky, G. Steiner, and J. S. Smolen, "Upregulation of cytokine receptors sTNF-R55, STNFR75, and sIL-2r in psoriatic arthritis synovial fluid," Journal of Rheumatology, vol. 25, no. 1, pp. 105-110, 1998.

[71] A. Mitra, S. K. Raychaudhuri, and S. P. Raychaudhuri, "Functional role of IL-22 in psoriatic arthritis," Arthritis Research \& Therapy, vol. 14, article R65, 2012.

[72] R. Sabat, S. Philipp, C. Höflich et al., "Immunopathogenesis of psoriasis," Experimental Dermatology, vol. 16, no. 10, pp. 779798, 2007.

[73] A. Spadaro, T. Rinaldi, V. Riccieri, G. Valesini, and E. Taccari, "Interleukin 13 in synovial fluid and serum of patients with psoriatic arthritis," Annals of the Rheumatic Diseases, vol. 61, no. 2, pp. 174-176, 2002.

[74] K. Wolk, E. Witte, E. Wallace et al., "IL-22 regulates the expression of genes responsible for antimicrobial defense, cellular differentiation, and mobility in keratinocytes: a potential role in psoriasis," European Journal of Immunology, vol. 36, no. 5, pp. 1309-1323, 2006.

[75] T. Loos, L. Dekeyzer, S. Struyf et al., “TLR ligands and cytokines induce CXCR3 ligands in endothelial cells: enhanced CXCL9 in 
autoimmune arthritis," Laboratory Investigation, vol. 86, no. 9, pp. 902-916, 2006.

[76] A. Fraser, U. Fearon, R. Reece, P. Emery, and D. J. Veale, "Matrix metalloproteinase 9, apoptosis, and vascular morphology in early arthritis," Arthritis \& Rheumatism, vol. 44, no. 9, pp. 20242028, 2001. 


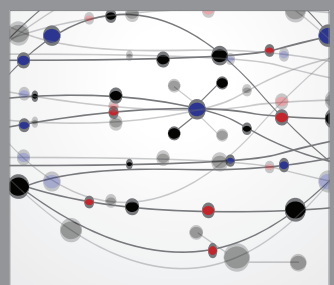

The Scientific World Journal
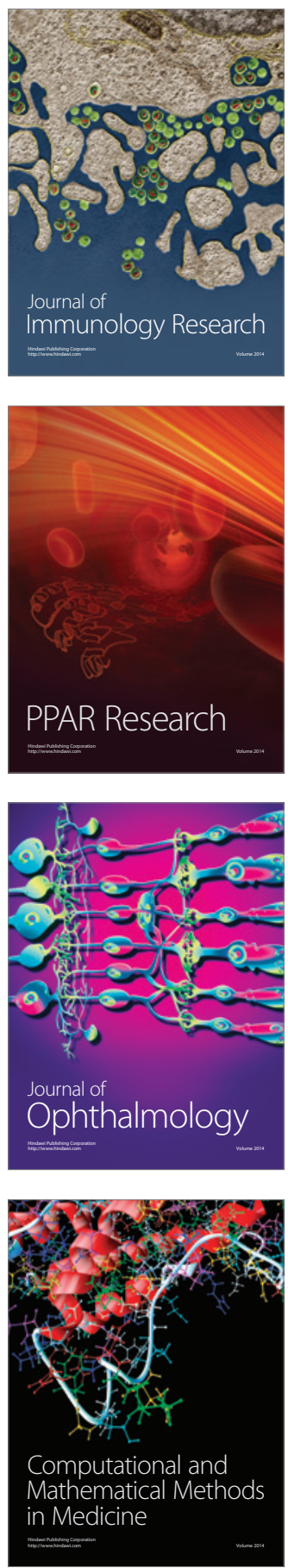

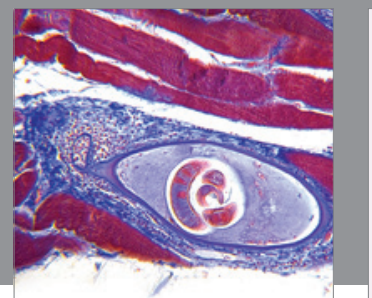

Gastroenterology

Research and Practice
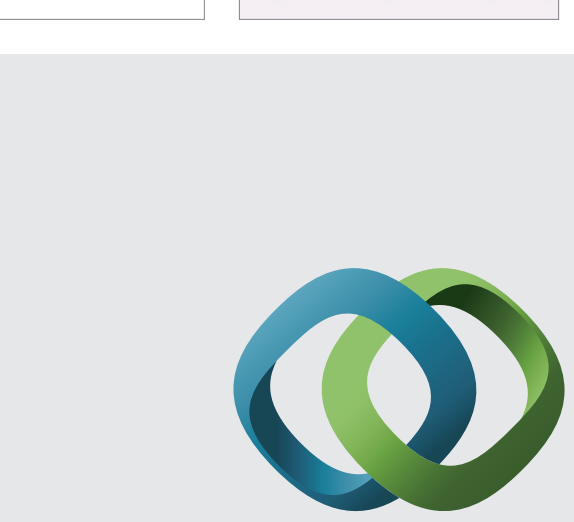

\section{Hindawi}

Submit your manuscripts at

http://www.hindawi.com
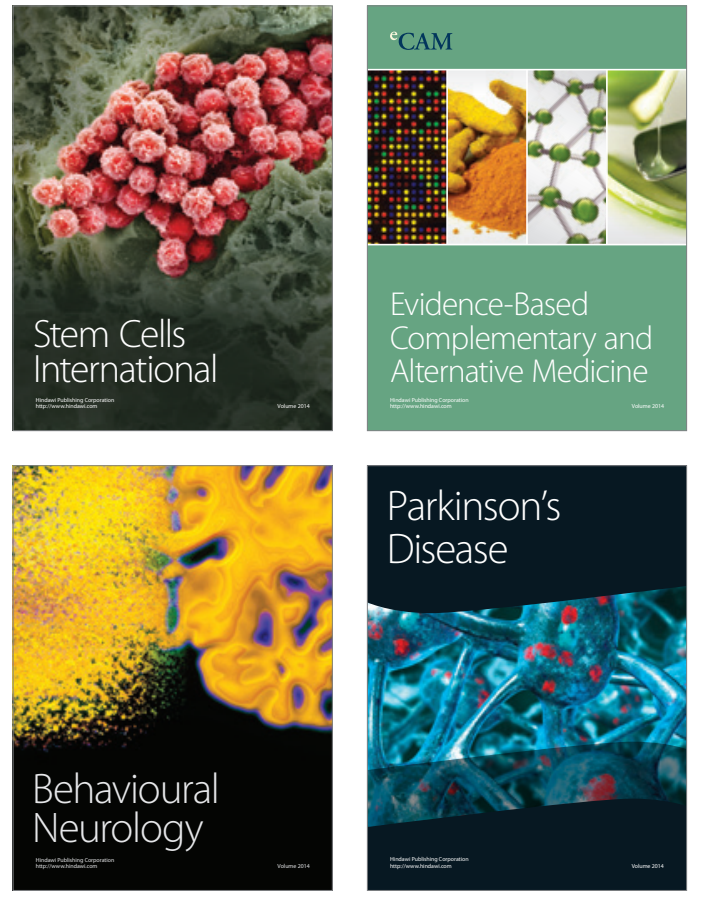
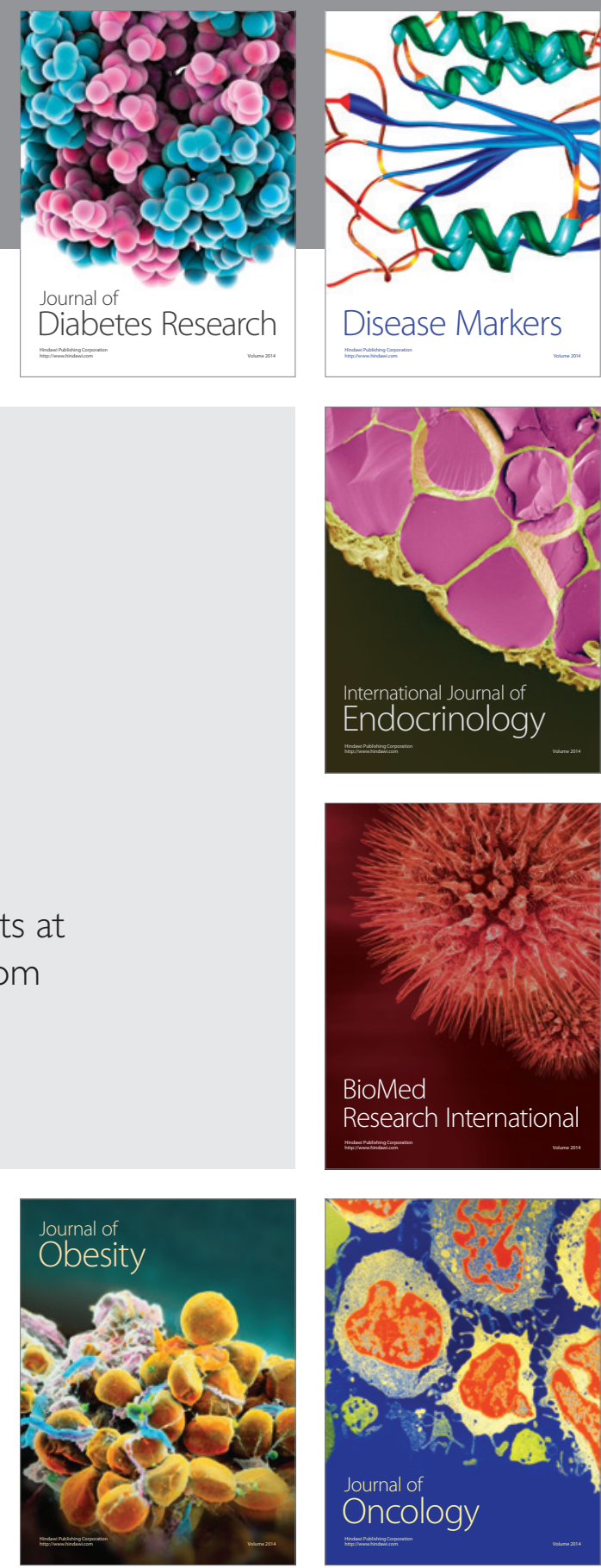

Disease Markers
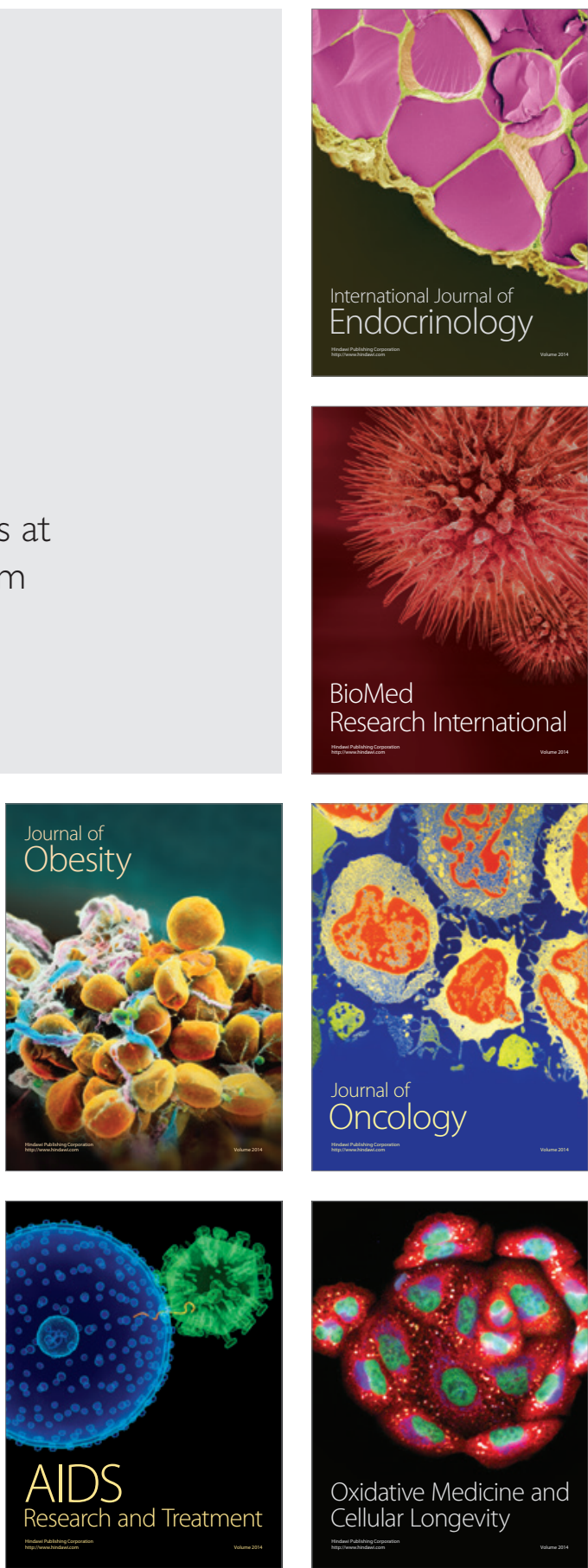